\title{
DERIVAÇÃO VENTRICULOPERITONEAL EM ADULTOS
}

\author{
J. JORGE FACURE * \\ NUBOR O. FACURE *
}

A derivação ventriculoperitoneal com válvula (DVP) tem sido utilizada com resultados satisfatórios por diversos autores. Nos trabalhos publicados a avaliação foi feita apenas em crianças, havendo também referências a alguns casos de pacientes adultos.

Animados pelos bons resultados obtidos com a DVP no tratamento da hidrocefalia infantil, passamos a empregar a mesma técnica cirúrgica em pacientes adultos.

\section{CASUISTICA E METTODOS}

Nossa casuistica compreende 17 hidrocéfalos com hipertensāo intracraniana (HIC) e um paciente com hidrocefalia de pressão normal. A idade variou de 15 a 72 anos (média de 35 anos). As válvulas utilizadas estão na tabela 1.

\begin{tabular}{lcc}
\hline & $\begin{array}{c}\text { Primeira } \\
\text { operação }\end{array}$ & Revisões \\
\hline \hline Holter de pressão média & 4 & 2 \\
Holter de pressão bajxa & 3 & - \\
Pudenz de pressão média & 2 & - \\
Ames & 9 & 1 \\
\hline
\end{tabular}

Tabela 1 - Válvulas utilizadas.

Os pacientes foram operados pela mesma equipe cirúrgica, no Hospital das Clinicas da UNICAMP (6 casos) e nos Serviços de Neurocirurgia dos Hospitais Beneficiência Portuguesa ( 8 casos) e Irmãos Penteado (4 casos), no periodo de fevereiro de 1969 a dezembro de 1972.

Etiologia - Os dados clínicos, laboratoriais e necroscópicos permitiram determinar a causa da hidrocefalia em parte dos casos (Tabela 2).

Departamento de Neurologia da Faculdade de Ciências Médicas da Universidade de Campinas, SP (Prof. Oswaldo Freitas Julião): * Neurocirurgiōes. 


\begin{tabular}{lc}
\hline Etiologia & Número de casos \\
\hline Neurocisticercose & 8 \\
Hemorragia subaracnóidea & 1 \\
Ependimoma do III ventrículo & 1 \\
Hidrocéfalo de pressão normal & 1 \\
\hline
\end{tabular}

Tabela 2 - Etiologia determinada em 11 dos 18 pacientes.

Nos 7 casos restantes não foi possivel estabelecer a causa da HIC; em dois pacientes foi demonstrada estenose do aqueduto cerebral, em um deles pela pneumoventriculografia e, pela iodoventriculografia, no segundo. Em 4 pacientes a iodoventriculografia mostrou bloqueio do tipo inflamatório ao nível da transição ventriculocisternal.

\section{RESUTADOS}

O periodo de seguimento variou de um mês a 4 anos. Seis pacientes faleceram. Os dados relativos às condições e seguimento dos pacientes, até fevereiro de 1973, figuram na tabela 3 .

Condiçōes atuais

\section{Número de casos}

Periodo de Média de seguimento seguimento (em meses) (em meses)

\begin{tabular}{lccc}
\hline HIC controlada, válvula funcionando bem & 10 & 2 a 48 & 14,6 \\
Desconhecidas & 2 & 10 e 18 & 14,0 \\
Obitos & 6 & 1 a 9 & 4,6 \\
\hline
\end{tabular}

Tabela 3 - Condicões dos pacientes em fevereiro, 1973.

Complicacões - Em um paciente, 4 meses após a DVP, verificamos mau enchimento da válvula; a radiografia simples do crânio mostrou estarem o cateter ventricular e a válvula fora de posição adequada. Realizamos revisão cirúrgica que consistiu em nova puncão ventricular e fixação da válvula; dois meses após o estudo radiológico demonstrou desconexão do cateter peritoneal ao nível do conector abdonıinal, sendo colocado novo cateter que dispensa o uso de conector. Outro paciente, um mês após a DVP, apresentou oclusão do cateter ventricular. Na revisão foi feita desobstrução, sendo mantido o mesmo cateter. 
COMENTARIOS

O uso de válvula unidirecional no sistema de derivação ventriculoperitoneal dificulta a oclusão da extremidade distal do sistema de drenagem ${ }^{1,5,6 \text {, }}$ $9,12,17,18,19$.

$\mathrm{Na}$ presente série não ocorreu oclusão do cateter peritoneal. Após a intervenção cirúrgica houve compensação da $\mathrm{HIC}$ em todos os casos. Para os dois pacientes cujas condições atuais desconhecemos o período de seguimento foi de 10 e 18 meses com bom funcionamento do sistema.

Devido ao longo trajeto do cateter peritoneal o método palpatório ${ }^{13},{ }^{16}$, utilizado para a verificação do funcionamento da válvula, pode, muitas vezes e sobretudo em adultos, deixar dúvidas quanto à existência de intercorrências bloqueantes.

O emprego de radioisótopos constitui método de valor para a avaliação da drenagem ${ }^{8}, 10,14,15$, fornecendo dados quanto a verificação da permeabilidade e, também, quanto a quantidade de líquido cefalorraqueano (LCR) drenado em determinado tempo.

Realizamos estudo pós-operatório com RIHSA (Radioiodinated Human Serum Albumin) em 5 pacientes. Com este método o período maior de avaliação do funcionamento da válvula foi de 6 meses. Para todos os casos o exame comprovou boa drenagem. Complicações relativamente raras e de fácil solução relacionadas com a introdução do isótopo no LCR foram des$\operatorname{critas}^{0,7}$.

Ames ${ }^{2}$ teve por duas ocasióes oportunidade de observar a cavidade peritoneal 24 e 28 meses após DVP referindo que não havia acúmulo de LCR e que o cateter permanecia livre, não formando aderências com as alças intestinais. Fischer e Shillito ${ }^{11}$ por ocasião de laparotomia também verificaram que o cateter não aderia às alças intestinais.

Dois pacientes de nossa casuística foram submetidos à necropsia, um deles faleceu um mês após a DVP e, o outro, 9 meses após a intervenção cirúrgica. O sistema de derivação permaneceu funcionando bem em ambos os casos. Não havia aderência e nenhum fenômeno inflamatório na cavidade peritoneal. Os cateter foram facilmente retirados, sendo verificado que suas extremidades estavam permeáveis. Um destes pacientes tinha volumoso ependimoma no III ventrículo; no outro caso havia acentuada dilatação ventricular e aracnoidite de base. Os óbitos foram atribuídos a broncopneumonia.

A oclusão do cateter ventricular, verificada em um paciente, ocorreu um mês após a DVP. O estudo radiológico revelou boa posição do cateter colocado na frente da sutura coronária, conforme recomendam Becker e Nulsen ${ }^{4}$. Na revisão foi retirado extenso coágulo do cateter ventricular.

Verificamos máu enchimento do sistema ventriculoperitoneal de Ames 2 em um paciente durante retorno ambulatorial, três meses após a intervenção 
cirúrgica. A radiografia simples do crânio revelou presença de lipiodol no interior do cateter ventricular (Fig. 1). Neste caso em que o método palpatório indicava funcionamento deficiente da DVP, realizamos estudo com RIHSA, tendo sido injetado o isótopo por punção do reservatório. Mapeamento com intervalo de trinta minutos comprovou boa drenagem (Fig. 2). O paciente foi acompanhado por um periodo de 5 meses, permanecendo sem manifestaçōes de HIC.

Complicaçōes infecciosas, que constituem graves intercorrências nas crianças submetidas à DVP, não foram registradas na presente série.

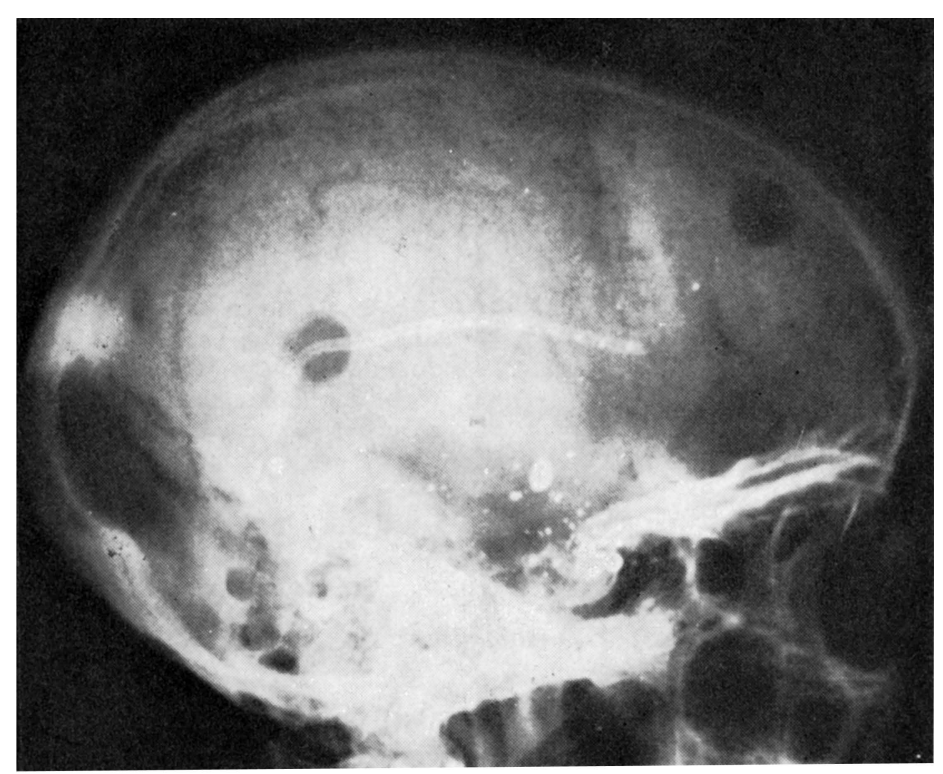

Fig. 1 - Radiografia simples de crânio. Presença de lipiodol no interior do cateter ventricular.

R E S M O

Apresentação de 18 pacientes adultos submetidos à derivação ventriculoperitoneal com válvula. Em 17 casos havia hipertensão intracraniana. Em 10 casos, com período de seguimento de 2 a 48 meses, os sistemas estão funcionando bem. Seis doentes faleceram, não sendo possivel estabelecer as condições atuais dos 2 restantes. Em 2 pacientes necropsiados, foi verificada permeabilidade da derivação e ausência de aderências e de peritonite. Oclusão da extremidade peritoneal do cateter não ocorreu em caso algum. 


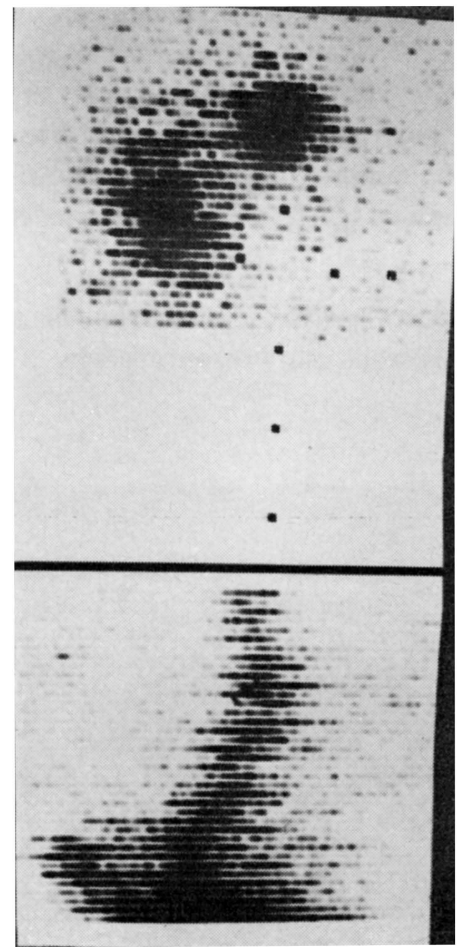

Fig. 2 - Mapeamento cefálico $e$ abdominal com intervalo de trinta minutos. Concentração do isótopo no ventriculo lateral, no reservatório e na cavidade peritoneal.

\section{S U M M A R Y}

Ventriculoperitoneal shunt in the adults

The cases of 18 adults patients operated on by ventriculoperitneal shunt with valve are reported. There was increased intracranial pressure in 17 cases. The shunt has functioned perfectly in 10 cases followed postoperatively from 2 to 48 months. Six patients died, being impossible the follow-up in the 2 remaining cases. Autopsy examination of 2 patients performed at 1 and 9 months after operation disclosed shunts to be patent. Adhesions or peritonitis were not found. Obstruction of the peritoneal and of the catheter did not occurred.

\section{REFERENCIA S}

1. ALMEIDA, G. M. \& PEREIRA, W. C. - Derivação ventriculoperitoneal com válvula no tratamento da hidrocefalia do lactente. Arq. Neuro-Psiquiat. (São Paulo) 27:308, 1969.

2. AMES, R. H. - Ventriculoperitoneal shunt in the management of hydrocephalus. J. Neurosurg. 27:525, 1967.

3. BARNES, B. \& FISH, M. - Chemical meningitis as a complication of isotope cisternography. Neurology (Minneapolis) 22:83, 1972. 
4. BECKER, D. P. \& NULSEN, F. E. - Control of hydrocephalus by valve regulated venous shunt: avoidance of complications in prolonged shunt maintenance. J. Neurosurg. 28:215, 1968.

5. CHAKRAVORTY, A. - Modified ventriculoperitoneal shunt in the treatment of hydrocephalus. J. Indian med. Ass. 44:293, 1965.

6. DAKTERS, J. G.; YASHON, D.; GROFT, T. J. \& WHITE, R. J. - Cerebrospinal fluid diversion. Arch. Surg. 96:56, 1968.

7. DETMER, D. E. \& BLACKER, H. M. - A case of aseptic meningitis secondary to intrathecal injection of $I^{131}$ human serum albumin. Neurology (Minneapolis) 15:642, 1965.

8. DI CHIRO, G. \& GROVE, A. S. - Evaluation of surgical and spontaneous cerebrospinal fluid shunts by isotope scanning. J. Neurosurg. 24:743, 1966.

9. FACURE, J. J. - Derivação ventriculoperitoneal com válvula no tratamento da hidrocefalia infantil. Arq. Neuro-Psiquiat. (São Paulo) 30:8, 1972.

10. FACURE, J. J.; FACURE, N. O.; CAMARA, A. J. \& OTERO, N. R. - Verificado funcionamento de derivaşões ventriculoperitoneais com válvula mediante emprego de radioisótopos: contribuição técnica pessoal. Arq. Neuro-Psiquiat. (São Paulo) 29:234, 1971.

11. FISCHER, E. G. \& SHILLITO Jr., J. - Large abdominal cysts: a complication of peritoneal shunts. Report of three cases. J. Neurosurg. 31:441, 1969.

12. HAMMON, W. M. - Evaluation and use of the ventriculoperitoneal shunt in hydrocephalus. J. Neurosurg. 34:792, 1971.

13. LEPOIRE, J. \& LAPRAS, C. - Traitment de l'hydrocephalie non tumorale du nourrison par la dérivation ventriculo-atriale. Neuro-chirurgie (Paris) 18:209, 1967.

14. McCULlough, D. C. \& LUESSENHOP, A. J. - Evaluation of photoscanning of the diffusion of intrathecal risa in infantile and childhood hydrocephalus. J. Neurosurg. 30:673, 1968.

15. MIGLIORE, A.; PAOLETT, P. \& VILLANI, R. - Radioisotopic method for evaluating the patency of the Spitz-Holter valve. J. Neurosurg. 19:605, 1962.

16. NULSEN, F. E. \& SPITZ, E. B. - Treatment of hydrocephalus by direct shunt from ventricle to jugular vein. Surg. Forum 2:399, 1952.

17. RAIMONDI, A. J. \& MATSUMOTO, S. - A simplifield technique for performing the ventriculo-peritoneal shunt. J. Neurosurg. 26:357, 1967.

18. WEISS, E. R. \& RASKIND, R. - Twenty-two cases of hydrocephalus treated with a silastic ventriculoperitoneal shunt. Int. Surg. 51:13, 1969.

19. WEISS, E. R. \& RASKIND, R. - Further experience with the ventriculo-peritoneal shunt: prophylatic antibiotics. Int. Surg. 53:300, 1970.

Clinica Neurológica - Faculdade de Ciências Médicas - Caixa Postal 1170 13100 Campinas, $S P$ - Brasil. 